\title{
Comment on 'Palovarotene reduces heterotopic ossification in juvenile FOP mice but exhibits pronounced skeletal toxicity"
}

\author{
Maurizio Pacifici ${ }^{1 *}$, Eileen M Shore ${ }^{2 *}$ \\ ${ }^{1}$ Translational Research Program in Pediatric Orthopaedics, The Children's Hospital \\ of Philadelphia, Philadelphia, United States; ${ }^{2}$ Department of Orthopaedic Surgery, \\ University of Pennsylvania, Philadelphia, United States
}

Abstract We are writing to communicate our concerns regarding the recently published study by Lees-Shepard et al. (2018).

DOI: https://doi.org/10.7554/eLife.43173.001

\section{Introduction}

Lees-Shepard et al. reported that palovarotene (a retinoid agonist) had severe side effects on growth plate and limb joints in an Acvr $1^{\mathrm{R} 206 \mathrm{H}}$ knock-in mouse model of fibrodysplasia ossificans progressiva (FOP; Lees-Shepard et al., 2018). We have a number of concerns about this publication. Lees-Shepard et al. write that "it is important for FOP therapeutics to exhibit an acceptable safety profile in juvenile patients": however, they used a retinoid drug delivery method that is never used in the treatment of patients, thus undermining their goal. Moreover, the mouse model used does not sufficiently mimic FOP patients.

*For correspondence: pacificim@email.chop.edu (MP); shore@pennmedicine.upenn.edu (EMS)

Competing interest: See page 2

Received: 29 October 2018 Accepted: 09 January 2019 Published: 30 January 2019

Reviewing editor: Clifford J Rosen, Maine Medical Center Research Institute, United States

(c) Copyright Pacifici and Shore. This article is distributed under the terms of the Creative Commons Attribution License, which permits unrestricted use and redistribution provided that the original author and source are credited.

\section{Discussion}

\section{Route of palovarotene administration}

Palovarotene was originally designed for oral administration (Hind and Stinchcombe, 2009), allowing for low and steady drug adsorption by the digestive system and an overall absorption efficiency of $50 \%$ to $65 \%$ of administered dose, typical of retinoids (Blaner and Olson, 1994). Instead, LeesShepard et al. injected the drug intraperitoneally (IP) every day for 4 weeks. This IP route of administration is known to invariably cause a sharp and sudden increase in circulating drug levels, resulting in a higher and faster $C_{\max }$ compared to oral delivery (Eaton and Gilbert, 2013). Indeed, palovarotene $\mathrm{C}_{\max }$ levels were found to be about 6-fold higher after IP injection compared to oral administration in mice (Clementia Pharmaceuticals, internal data). Circulating retinoids are quickly taken up by tissues and cells (Cullum and Zile, 1985), and cells accumulate retinoids in large amounts intracellularly (Kurlandsky et alo, 1995; Randolph and Simon, 1997) where their action on cell function and phenotype can last hours to days (Chen and Gudas, 1996). Thus, daily IP injections are expected to result in ever increasing and possibly confounding drug effects over time. Lees-Shepard et al. stated that they used "palovarotene doses....that correspond to approximate adult human equivalent doses of $3.6 \mathrm{mg}$ and $7.2 \mathrm{mg}$ " under testing in ongoing efficacy and safety study of palovarotene for the treatment of FOP being conducted by Clementia Pharmaceuticals (https://clinicaltrials.gov/ct2/ show/NCT03312634. This trial has recently entered phase 3). However, the IP administration changed the effective dose and undermined the goal of testing a clinically relevant treatment. 


\section{FOP mouse model}

Lees-Shepard et al. utilized a conditional mouse model in which the FOP causative gene was activated in Pdgfro-expressing cells by mating floxed Acvr $1^{\mathrm{R} 206 \mathrm{H}}$ mice with Pdgfro-Cre mice. Those cells were described as a subpopulation of progenitor cells particularly sensitive to effects of the mutation. This mouse model is at sharp variance with FOP patients in which the mutant ACVR1 ${ }^{\mathrm{R} 206 \mathrm{H}}$ gene characterizes the majority of, if not all, cells. Thus, data obtained with the Pdgfro-Cre mouse model may be skewed by targeting a specific subpopulation of cells that could also be affected by wildtype cells, with the wild-type cells likely outnumbering the cells in the specific Acvr $1^{\mathrm{R} 206 \mathrm{H}}$ subpopulation and interacting with them. Thus, the model does not faithfully reproduce the overall genetic makeup and cell and tissue responses in FOP patients. While Lees-Shepard et al. observed that Pdgfr $\alpha+$ cells contributed to heterotopic ossification $(\mathrm{HO})$ in their model, it is not known whether this specific cell population is clinically relevant in FOP patients. Further, Lees-Shepard et al. presented no data showing that targeted Pdgfr $\alpha+$ cells were present in the growing skeleton.

\section{Effects on growth plates and joints}

These latter issues are particularly relevant to the severe effects on growth plates and joints reported by Lees-Shepard et al. Given that the Pdgfro gene is not known to be expressed in chondrocytes (Hamilton et al., 2003), it is nearly certain that growth plate and articular chondrocytes were not targeted by Pdgfro-Cre and remained largely, if not totally, wild-type. Lees-Shepard et al. included no data to demonstrate that Pdgfro-Cre had targeted growth plate and joint chondrocytes. Studies dating back decades have established that cartilage is sensitive to systemic retinoid levels (Wolbach and Hegsted, 1953). In our studies (Chakkalakal et al., 2016; Shimono et al., 2011), we did observe a slight growth retardation of about $10 \%$ in control wild type mice after oral palovarotene administration, although their growth plates remained open and there were no obvious effects on their joints. Notably, there were no obvious growth retardation and growth plate effects after oral palovarotene administration in our Prrx1-Cre; Acvr $1^{\mathrm{R} 206 \mathrm{H}}$ mutant mice in which the entire limb mesenchymal cell population was targeted, including skeletal cells. The higher tolerance of mutant growth plates was likely due to higher basal levels of canonical BMP signaling activity. As we pointed out previously (Chakkalakal et al., 2016), this provides support to the notion that palovarotene may be quite safe for - and well tolerated by - FOP patients, as supported by the announcement of Phase 2 Part B data from the ongoing efficacy and safety study being conducted by Clementia (Clementia Pharmaceuticals, 2018).

\section{Conclusions}

In sum, the severe side effects on growth plates and joints observed by Lees-Shepard et al. are likely the results of: (i) the route of drug administration; (ii) excessive palovarotene levels and effects likely caused by the daily IP administration; and (iii) reliance on a mouse model that does not mimic FOP patients, including apparent lack of mutation expression in cartilage. We strongly recommend that data and conclusions in that study should be considered and interpreted with caution with regard to drug effects and action in skeletal tissues and for relevance to ongoing clinical studies.

\section{Additional information}

\section{Competing interests}

Maurizio Pacifici: MP is a consultant for Clementia Pharmaceuticals. The other author declares that no competing interests exist.

Author contributions

Maurizio Pacifici, Eileen M Shore, Conceptualization, Formal analysis 
Author ORCIDs

Maurizio Pacifici (iD https://orcid.org/0000-0001-6854-4942

Eileen M Shore (iD) http://orcid.org/0000-0003-2609-6971

\section{References}

Blaner WS, Olson JA. 1994. Retinol and retinoic acid metabolism. In: Sporn MB, Roberts AB, Goodman DS (Eds). The Retinoids: Biology, Chemistry, and Medicine. Second Edition. New York: Raven Press. p. 229-255.

Chakkalakal SA, Uchibe K, Convente MR, Zhang D, Economides AN, Kaplan FS, Pacifici M, Iwamoto M, Shore EM. 2016. Palovarotene inhibits heterotopic ossification and maintains limb mobility and growth in mice with the human ACVR1 $1^{(\mathrm{R} 206 \mathrm{H})}$ ) Fibrodysplasia ossificans progressiva (FOP) mutation. Journal of Bone and Mineral Research 31:1666-1675. DOI: https://doi.org/10.1002/jbmr.2820, PMID: 26896819

Chen AC, Gudas LJ. 1996. An analysis of retinoic acid-induced gene expression and metabolism in AB1 embryonic stem cells. Journal of Biological Chemistry 271:14971-14980. DOI: https://doi.org/10.1074/jbc.271. 25.14971, PMID: 8663043

Clementia Pharmaceuticals. 2018. Clementia announces updated phase 2 part B data on palovarotene for FOP. Globe Newswire. https://globenewswire.com/news-release/2018/09/26/1576476/0/en/Clementia-AnnouncesUpdated-Phase-2-Part-B-Data-on-Palovarotene-for-FOP.html [Accessed December 9, 2018].

Cullum ME, Zile MH. 1985. Metabolism of all-trans-retinoic acid and all-trans-retinyl acetate. Demonstration of common physiological metabolites in rat small intestinal mucosa and circulation. The Journal of Biological Chemistry 260:10590-10596. PMID: 4030759

Eaton DL, Gilbert SG. 2013. Principles of toxicology. In: Klaassen CD (Ed). Casarett and Doull's Toxicology: The Basic Science of Poisons. Eighth Edition. London: McGraw-Hill.

Hamilton TG, Klinghoffer RA, Corrin PD, Soriano P. 2003. Evolutionary divergence of platelet-derived growth factor alpha receptor signaling mechanisms. Molecular and Cellular Biology 23:4013-4025. DOI: https://doi. org/10.1128/MCB.23.11.4013-4025.2003, PMID: 12748302

Hind M, Stinchcombe S. 2009. Palovarotene, a novel retinoic acid receptor gamma agonist for the treatment of emphysema. Current Opinion in Investigational Drugs 10:1243-1250. PMID: 19876792

Kurlandsky SB, Gamble MV, Ramakrishnan R, Blaner WS. 1995. Plasma delivery of retinoic acid to tissues in the rat. Journal of Biological Chemistry 270:17850-17857. DOI: https://doi.org/10.1074/jbc.270.30.17850, PMID: 7629087

Lees-Shepard JB, Nicholas SE, Stoessel SJ, Devarakonda PM, Schneider MJ, Yamamoto M, Goldhamer DJ. 2018. Palovarotene reduces heterotopic ossification in juvenile FOP mice but exhibits pronounced skeletal toxicity. eLife 7:e40814. DOI: https://doi.org/10.7554/eLife.40814, PMID: 30226468

Randolph RK, Simon M. 1997. Metabolism of all-trans-retinoic acid by cultured human epidermal keratinocytes. Journal of Lipid Research 38:1374-1383. PMID: 9254063

Shimono K, Tung WE, Macolino C, Chi AH, Didizian JH, Mundy C, Chandraratna RA, Mishina Y, EnomotoIwamoto M, Pacifici M, Iwamoto M. 2011. Potent inhibition of heterotopic ossification by nuclear retinoic acid receptor- $\gamma$ agonists. Nature Medicine 17:454-460. DOI: https://doi.org/10.1038/nm.2334, PMID: 21460849

Wolbach SB, Hegsted DM. 1953. Hypervitaminosis A in young ducks: The epiphyseal cartilage. Archives of Pathology 55:47-54. 